\title{
Conceptual and Organizational Differences within the Educational System - Necessary for the Inclusion of Children with Autism Spectrum Disorders within Typical Classrooms
}

\author{
Phd. Grenada Hoxhaj \\ "Kristal" University \\ h.geranda@yahoo.com
}

\section{Doi:10.5901/mjss.2014.v5n2p389}

Abstract

\begin{abstract}
Cases of children with Autism Spectrum Disorders are rapidly spreading throughout the world. Despite the lack of statistics, this is a continuously growing phenomenon even in Albania. One of the challenges associated to this disorder is the inclusion of children within the Educational System. What are the difficulties encountered by children with ASDs and by their parents? How should we organize work in order to achieve their inclusion within typical classrooms? Developing countries experience has introduced us to several types of treatment which might be the base of our Educational System. Our real challenge through the treatment is that, each of them displays unique characteristics. We lack the psycho-pedagogical experience upon which to compile our educational programs for our institutions, as we lack the established practice for this. As a result, the number of children attending school is extremely limited and more kids, wander different institutions, or stay indoors. The aim of this study is to bring in information showing the importance of making conceptual and organizational changes within our educational system, so as to make it possible the inclusion of children with ASDs within typical classrooms.
\end{abstract}

Keywords: Autism Spectrum Disorders, Individualized Programs, Psycho-pedagogical treatment, Inclusion, Conceptual differences.

\section{Introduction}

Autism spectrum disorder (ASD) and autism are both general terms for a group of complex disorders of brain development. These disorders are characterized, in varying degrees, by difficulties in social interaction, verbal and nonverbal communication and repetitive behaviors. With the May 2013 publication of the DSM-5 diagnostic manual, all autism disorders were merged into one umbrella diagnosis of ASD. Previously, they were recognized as distinct subtypes, including autistic disorder, childhood disintegrative disorder, pervasive developmental disorder-not otherwise specified (PDD-NOS) and Asperger syndrome.

ASD can be associated with intellectual disability, difficulties in motor coordination and attention and physical health issues such as sleep and gastrointestinal disturbances. Some persons with ASD excel in visual skills, music, math and art.

Autism appears to have its roots in very early brain development. However, the most obvious signs of autism and symptoms of autism tend to emerge between 2 and 3 years of age.

As a result of several reasons, the Albanian Educational System is not prepared to face autism challenges. One reason is lack of knowledge about this phenomenon, not only considering it from the educational system, but also from the medical one. Secondly, lack of psycho-pedagogical treatment aggravates the disorder - consequently, the child is unprepared for primary education. Thirdly, the trauma of the parent while facing the complexity of the disorder and the lack of specialized assistance to help parents, negatively affects the parent. An increase in cases with autism led to the awareness of our society and our institutions regarding information about autism, even though difficult to be treated as a result of the lack of specialized institutions covering this field. Although lack of information is not a major problem these days, the right psycho-pedagogical treatment is an obstacle. Conceptual change in the educational system and an efficient framework for the complete treatment of children with ASDs is necessary. As it happens only in the first grade to see parents trying to enroll their autistik children, autism needs special attention. With reason, techers find themselves before a difficult decision - if to enroll them or not? Is it possible for the teacher to manage two or more autistic children in the same classroom?

This exploratory research aims at exploring the individual treatment of each child and the reality of their confrontation to the educational system. Its objective is the study of the relationship between the disorders displayed by the child and the lack of the appropriate framework within the educational system. 
Methodology, this study is based mainly in:

- Literature study for teaching children with ASDs

- Pupils` monitoring as a study case

- Interviews with parents and teachers

Monitoring and semi-structured interviews with parents and teachers have been selected as a study tool.

The descriptions of children with Autism Spectrum Disorders who are being studied are as follows:

Boy A, 7 years old recognizes letters, knows writing and reading. He recognizes and writes numbers, but he has difficulty in operating with them. He moves his head and his hand as a stereotype. He has a limited attention span.

Boy B, 9 years old, non-verbal. He works by stimuli and modeling. He has limited attention. His attention is not driven by the teacher's voice. He refuses to work and becomes emotionally irritated.

Girl C, 9 years old, non-verbal. She is dominated by strong stereotype, such as looking at her hand and tiptoeing. She lacks concentration. Her working span is limited. Often she is overwhelmed by negative emotions, followed by objection and crying.

\section{Disorders Problematic Prevents the Involvement of Children with ASDs in Classrooms with Typical Children}

Behavioral disorders are the most evident, vulnerable and major barrier for the inclusion of children with autism in classrooms with normal children. Hyperactivity, concentration deficit, aggression, auto-aggression, communication deficits, low concentration ratio and stereotypes are some of the most problematic symptoms within school environment.

"Behavior includes all human activities - actions, interactions, thinking and speaking- and environment includes social and physical, external and internal events, as life experience. The biggest challenge for educators is behavior management along with the difficulty or impossibility of the child to learn."( Allan and Nesta Ferguson, 2011, Pg . 3)

Most children with ASDs, do not fully experience all senses, which teach typical children to interact with the world. Many of these children cannot use more than one sense at a time. They become overwhelmed when they have to use multiple senses together.

There are many kinds of ASDs treatments being executed all over the world, which are based on different phylosophies, but all of them aim the softening of autism symptoms. It is not clear yet to what extent are treatments effective, although they have been conceived and framed by proper specialists and therapiests are graduated in genuine schools.

This leads to social and emotional disconnections, making it very difficult or even impossible to develop friendship. You see, these children seem different from others, because the do. Children with ASDs do not think or feel the same as other children. They feel socialy and emotionaly disconnected. This dsconnection comes as a result of the behavorial disorder starting from the impulsive behaviors and emotional variability as they are unable to focus and social izolation.

They become easily distracted by anything they hear, see or feel, making it impossible for them to concentrate. As a result, they turn into slaves of their environment. They are socially and emotionaly disconnected. They cannot intuit the connection between movement and feelings as they cannot feel their own body movement.

Refering to our study, time to time, boy A wants to stand up and move around the classroom leaded by a stereotype, stop work or not working if not stimulated. Boy B has a limited working span, only on interrupted lines or dots, plays with his favourite object or with his fingers, each time he stops working. Often he makes noises when he does not want to proceed with the work. Girl $\mathrm{C}$ is withdrown and tiptoeing, manipulating her fingers before her face. She can not concentrate without being held by her hand.

\subsection{How is behavior treated in school environment?}

The majority of children with autism spectrum disorders will at least display many challenging behaviors at school. And these problems are not going to disappear by the time the child matures, and it is necessary behavior modification. Studies for the effectiveness of the problematic behavior modification approach are quite encouraging. When children with ASDs enter in the classroom they sustain "a behavioral plan". This plan involves another plan of "positive behavioral support"; especially strategies for the reduction of destructive behavior and "not related to the given tasks", and the increase of productive behaviors. The fact that a child comes up with a "behavioral plan" does not necessarily mean that he/she will cause a major behavioral problem while in the classroom. This means that problems related to behaviors are officially identified and that there exists a way to treat them. (D. Fein \& M. Dunn, 2007 Pg. 281)

It does not exist a behavioral plan for Albanian children with ASDs. The situation is more difficult for the teacher, 
whose role is to face to a certain behaviors without knowing the behavioral disorders of his/her pupil, and without even knowing how to treat him/her. Not only does the pupil lack the behavioral plan, but it is not even framed later by, because of the lack of competent structures.

When teachers are asked how they treat autistic behaviors, they state that it is impossible for them to do this, mentioning various factors:

It is quite difficult to know since from the first interview how they consider these kids' difficulties, but it is clear enough that they try to avoid their responsibility. Teachers mention various disorders, which they don't know how to deal with: he stands up, moves his hands in a strange manner, screams, claps his hands or different objects, he gets irritated if asked to proceed with his task.

$>$ Classrooms have a big number of pupils.

$>$ They are first-grade pupils, and consequently there are many of them who need individual help.

They do not know children with ASDs and do not how to treat them.

\subsection{It is often difficult for children with Autism Spectrum Disorders to adapt to new environments.}

In these cases, it is necessary for the child to be assisted by a psychologist or by his parent, in order to moderate this difficulty. It was stated by our focus group of parents that parents accompanied their children themselves, or they provided the assistance of another person, as they were aware of the reaction of their child. The focus group of parents agreed about assisting the child by a trained specialist to monitor the child behavior. They think that in case of behaviors with difficulty in managing, children`s assistance by a specialist would be an opportunity for their improvement.

In this case, we are talking about two difficulties- it is impossible to find a trained specialist to assist the child, and the second is the financial aspect.

In the case of the kids of this study, boy A and girl C are accompanied by an inexperienced assistant, while boy B is assisted by his mother. It seems like they just accompany them, take them out of the classroom when they get irritated, trying to maintain silence in classrooms. When asked how they manage behavior, assistants say that they walk kids out of the classroom if they are irritated, and bring them back when calmed. As teachers feel under pressure, they reduce the amount of educational activities required to children with ASDs.

\subsection{The deficiency of the psycho-pedagogical treatment in children with Autism Spectrum Disorders.}

Another important element of behavioral adaption and improvement is intensive intervention since an early age. This is not possible in Albania, as a result of the lack of genuine institutions and specialized staff for this treatment. The only service available in our country is the developmental therapy, which is performed from one hour per week to one hour per day. This therapy is more productive if the child is the subject matter in the beginning of the intervention, so as to help them to be willing to learn, to frame major communicative skills and the reduction of behaviors that could interfere with learning. Those children lucky enough to attend this therapy are trained under an intensive format (20-40 hours per week) by one or more trained therapists, supervised by Behavior Analysts and overseen by a behavioral psychologist.( Jennifer Krumins, ( 2008 ), "One Step at a Time ABA and Autism in the Classroom", Publisher: Autism Aspirations, USA, Pg. 18 )

Another deficiency which reduces the quality of the intervention is that therapists work with the child on their own, without the assistance of the parent and moreover, there is a lack of work coordination among colleagues.

Focus groups of parents have noticed that: a child works with the same therapist for many years. The therapy consists of repetition of similar activities, using the same tools. It does not exist a project plan. So, the parent lacks a project plan, and he/she also lacks data about the child's performance or difficulties he could have experienced. There is no cooperation between the teacher and the therapist in cases when the child attends school- a gap which the parent tries to fill, but when he/she tells the teacher about the child's performance during the therapy, he often faces the reply: "he doesn't react the same here". He/she often reluctantly goes to therapy sessions and he is often peeved during the time he spends there.

The principle of this paper is not- "the child must learn according to individual needs", but that- "there are many activities that therapists consider to be performed". According to what is mentioned above, the child tries to attend the school environment, aggravating in this way his disorders and facing the lack of the right psycho-pedagogical treatment.

Teachers asked about the way they work with children with ASDS, mention many of their inabilities- he does not understand me, he doesn`t listen to me, he doesn`t speak to me, he doesn`t obey me. "It is not possible to work with 
them."- this is the thought that nominates the teacher.

Referring to kids under study, we noticed that: Boy $A$, answers to almost every question, but he is sitted in the last row of desks and rarely asks him about anything. Boy B, is scarcely observable, as his mother is assisting him. Girl C, has no communication with her teacher. The teacher constantly asks the assistant to walk the child out as a result of minor inconvenience.

\section{Teaching a Student with Autism}

Teaching a student with autism is a professional challenge and an opportunity to grow as an educator. These children will relate to others in a different way, perceive the environment differently, communicate with greater difficulty or not at all, and each child with autism has a unique learning style with an original ability/disability profile. There is no neat and concise, pre-packaged program that educators can pull off of a shelf when they are called upon to educate a child with autism. Around the globe the incidence of autism diagnoses is soaring, parents are begging for schools to meet their children's needs and school boards are desperately seeking ways to do just that. The stakes are high during these times; our children need more: more differentiation in instruction, more varied teaching strategies and more trained staff that are able to address the particular autistic learning styles. Our professionals need more as well: more training, more support and more time.

Many things can help a person with autism; education plays a key role in retraining the brain and establishing the tools that individuals need to manage their own health, emotions, relationships and intellect. It is imperative that educators continue to look into best practices and scientific research to determine what we can do to educate children that live with autism and to inspire them a drive to continue to grow and to learn on their own. (Jennifer Krumins, ( 2008 ), "One Step at a Time ABA and Autism in the Classroom", Publisher: Autism Aspirations, USA,Pg. 8)

Teachers' interviews have introduced us to various concerns that make the teacher's job more difficult. When asked how much do they know about autism phenomena, they answered "a few information" or "no information at all". They were informed accidentally, by the media or by people they knew. They have not been professionally trained for this phenomenon, although lately some of these treatments have developed. But school directories do not own any orientation manuals, nor do they posses any manuals for the treatment of autism symptoms within the school environment.

When asked about the assistance of the psychologist at schools, teachers answer that it is really impossible. The psychologist must cover problems of two thousand pupils, which makes the psychologist's assistance impossible. The good will to attend and accompany children while they try to understand and execute learning tasks turns into a challenge for the teacher because of the big number of pupils within a classroom, which varies from 35 to 45 . Besides the treatment of the child with ASDs, another concern is the problematic of this age group.

According to the interviews, teachers need training so as to have more information about ASDs, orientation manuals to help them schedule their work according to the needs of children, and assistance in order to manage their behaviors and learning difficulties.

What would actually help them? They said: a plan scheduled according to the needs, skills and difficulties of children with ASDs. This would considerably help teachers organize their work in a way so as to involve children with ASDs in classrooms together with their peers.

Miller highlights: "We still maintain that there is a basic drive in all children-no matter how withdrawn or disorganized they may be-to find a way to cope with a confusing and inconstant world. Children with autism express this drive in spite of major challenges with experiencing their bodies and how they relate to the world. Our task is to help these children use every capacity or fragment of capacity to achieve this goal of coping. This becomes possible when we introduce both order and carefully gauged disorder into their lives. Introducing order helps cohere the children's fragmented functioning while introducing carefully gauged disorder helps them cope with change." (A. Miller \& K. Chrétien, 2007, Pg .19)

Is it possible to argue about teaching children with ASDs within the school environment? This question was asked to teachers and parents. Parents answered that it was impossible because teachers did not pay attention to their kids. Teachers answer that teaching these kids is impossible as they do not know how should they them. 


\section{The Alarming Spread of the Disorders - A Strong Signal for Necessary Changes within the Educational System}

Since in Albania we lack statistics about the spread of autism, we refer to literature whose authors were referred to statistics.

Melillo argues that: "During this year, 1.5 million children who have entered school, 1 out of 6 five or six aged children are diagnosed with several neurological disorders which affect their ability to learn and their social interaction. This is a rising tendency. In the United States, during the last decade, the number of children attending special education has grown 46,9 percent; in Florida it has grown from 6 percent to 13,2 percent-more than five years ago. (R. Melillo, 2010, Pg.15)

Changes within the Educational System must be conceptual as much as organizational. This needs an in-depth study of an applied approach currently successful around the world, a professional training of the specialists and of course the necessary time for the implementation of these changes. From this point of view, the most adequate issue is the treatment of those children who are at the age of primary school.

In which way is work organized within institutions? The focus group argues that it is not. Children go to school full time or part time, they partly do or they do not do their homework at all. Later on, the child assists individual therapies; it does not have to do with what he/she performs at school. So, there is not a program for children`s treatment.

What would be the most effective help for the treatment of your children? The focus group answered that there must change many aspects within the Educational System, but what must at least be conducted is cooperation between the teacher, the therapist, the psychologist and parents must.

When asked if what would help with the inclusion of their children in classrooms of normal children, the focus group of parents answered:

- More knowledge about disorders and symptoms by the pedagogical staff

- Children assistance by a specialist that can manage their behavior and answer for their specific needs

- Teamwork between the therapist, school staff, psychologist and parents

- A concrete work plan conceived according to children`s specifics, after they have been observed

In Albania, we lack specialized structures for evaluating and drawing up individualized programs, that is why people working with children can and must cooperate among each other so as to coordinate their work.

\section{Findings and Conclusions}

For parents, school attendance was a very important step toward normalization or inclusion of autistic children in classrooms with normal children.

They had encountered two types of teachers:

- Those who tried to avoid these children as a result of the lack of knowledge about the phenomenon and about disorders' characteristics.

- Those who were ready to work with this category of children but did not know how to.

During group discussions it was emphasized the importance of the distinction between the terms "attendance" and "involvement", related to children with disorders. The majority of parents considered that the system could just offer the attendance of school.

The inclusion of children within the educational system was impossible because of the lack of psycho-pedagogical assistance for their specific needs.

Behaviors that cannot be managed by the teacher alone- who has to cope with a big number of pupils in each classroom- leads to two alternatives: a lower number of pupils in those classrooms with autistic children, or, assistance by a psychologist or a family member.

As mentioned above, everyday, children with ASDs- at the age of Primary School- miss the chance to become involved in classrooms with normal children, by staying indoors and creating a very problematic setting for the mother, who deals alone with the heavy burden of the disorders and that of the family- a burden extending from family to society.

\section{References}

Allan and Nesta Ferguson. (2011), "UK ABA Autism Education Competence Framework" Harold Hyam Wingate Foundation, PorticisUK 
Arnold Miller with Kristina Chrétien, ( 2007 ), "The Miller Method” by Jessica Kingsley Publishers, UK Deborah Fein, \& Michelle Dunn, ( 2007 ), "Autism in Your Classroom", Woodbine House, USA. Heward.W.L. et al. (ed. 2005 ). "Using Science to Improve Educaitonal Outcomes for All Students" The Ohio State University. USA Jennifer Krumins, ( 2008 ), "One Step at a Time ABA and Autism in the Classroom", Publisher: Autism Aspirations, USA.

Lone Gammeltoft and Marianne Sollok Nordenhof, ( 2007 ), "Autism, Play and Social Interaction”, By Jessica Kingsley Publishers, London, UK.

Marshall and Rossman.( 2006 ). Forum: Qualitative Social Research, Vol.9. 13-September 2008. Deutsch. Espanol.

Mulick, James A. ( 2006 ). "Positive Behavior Support and Applied Behavior Analysis". The Behavior Analyst 29. USA

Robert Melillo, (2010), "Disconnected Kids", Published by the Penguin Group. USA

Thompson, T. ( 1984 ). "The examining magistrate for nature: a retrospective review of Claude Bernard's An Introduction to the Study of Experimental Medicine". Journal of the Experimental Analysis of Behavior 2

\section{Websites}

https://www.autismspeaks.org

https://stopcallingitautism.org/content/presentations/Juan-Rodriguez-SCIA-AutismOne-2013.pdf

https://www.autismtraining.com.au/public/index.cfm?action=showPublicContent\&assetCategoryld=1022 